\title{
1977: EM TORNO DE UM MOMENTO-CHAVE DO SURGIMENTO DA SOCIOLINGUÍSTICA ${ }^{1}$ NA FRANÇA ${ }^{2}$ \\ 1977: CONCERNING TO A DECISIVE MOMENT OF THE EMERGENCE OF SOCIOLINGUISTICS IN FRANCE
}

Françoise Gadet ${ }^{3}$

Resumo: Em 1977, um número da revista francesa de Linguística Langages, que tratava do marrismo, desempenhou, no contexto acadêmico francês, um papel determinante no surgimento de uma nova subdisciplina da Linguística, a Sociolinguistica. Examinam-se aqui, de modo geral, as modalidades de surgimento de uma nova subdisciplina (fatores negativos e fatores positivos) e o papel que os grandes debates temáticos exercem nestes domínios. Especificamente, situam-se alguns dos atores desse processo dos anos $1970 \mathrm{com}$ o objetivo de compreender a relação com as teorias anteriores, sobretudo a oposição aos estudos saussurianos, examina-se a proximidade/confrontação com a Análise do Discurso, outra subdisciplina nascida no mesmo momento e que compartilha grande parte dos atores. Busca-se, por outro lado, compreender questões veiculadas por essa nova disciplina, que se estabelece a partir da relação entre a reflexão em torno da Linguística Geral e intervenção social do cidadão-linguista.

Palavras-chave: Marxismo, Marrismo, Linguística, Sociolinguística, Análise do Discurso.

Abstract: During the year 1977 a number of the french Journal of Linguistics named Langages, which discussed on Marrism had an important role for the emergence of a new discipline of Linguistics, 'Sociolinguistics.' We investigate, here, the modalities of the birth of a new discipline (positive and negative aspects) and the importance that thematic approaches on the subject acquired in this field. Situating some actors of this process during the years 1970 we try to understand relationships with early theories, mainly the opposition

1 Este artigo foi apresentado, originalmente, pela autora no Colóquio 'Um Paradigma Perdido: a linguística marrista' realizado na Universidade de Lausanne e posteriormente publicado em Cahiers de I'LSL nº 20, 2005.

2 Tradução de Maria Helena Martins da Rosa. Revisão de tradução de Patrícia C. R. Reuillard e revisão técnica de Ana Zandwais, UFRGS.

3 Docente e pesquisadora da Universidade de Paris X. 
to approaches on Saussure 's studies, and we examine also the neighboring with Discourse Analysis, a discipline that emerged at the same moment and which share the same actors with Sociolinguistics. We aim to understand questions produced by this new discipline which is established considering a relationship between general linguistics and the social contribution of the citizen-linguist.

Keywords: Marxism, Marrism, Linguistics, Sociolinguistics, Discourse Analysis

\section{Introdução}

Minha participação no tema deste colóquio expressará um ponto de vista externo, pois não sou especialista nem na linguística de Marr ou no marrismo, nem na linguística soviética dos anos 1920-1930, nem na polêmica que se prolongou, em 1950, com o texto de Stalin "O Marxismo e os Problemas da Linguística", nem no ressurgimento atual do marrismo na Rússia.

O que vou desenvolver aqui se refere às repercussões que os debates sobre o marrismo na URSS tiveram na Linguística francesa durante os anos 1970. Esse episódio parece-me, de fato, digno de ser novamente considerado, ignorando os anos passados (aproximadamente o mesmo tempo que o decorrido entre a intervenção de Stalin e a publicação do número da Revista ( Langages), porque ele repete um nó de problemas inerentes ao desenvolvimento da Linguística na França.

Embora eu esteja convencida de que não se pode olhar o debate sobre a língua na URSS nessa época como se fosse uma pura controvérsia científica, não considero contudo inútil retomar a alguns dos problemas então debatidos, dado o papel que representaram no surgimento do campo da Sociolinguística francesa em paralelo ao da Análise do Discurso.

\section{$2 \mathrm{O}$ contexto acadêmico do número de langages sobre o marrismo}

O número 46 da Revista Langages é publicado em 1977. Intitula-se Langage et classes sociales: le marrisme e é organizado por Jean-Baptiste Marcellesi, sociolinguista reconhecido que foi também, juntamente com Jean Dubois, um dos instigadores da Análise do Discurso na França. Além de uma tese defendida em 1970 sobre o Congresso de Tours, a primeira Tese 
de Análise do Discurso orientada por Jean Dubois, Marcellesi publicou três anos antes (1974) uma obra escrita em colaboração com Bernard Gardin, Introduction à la sociolinguistique. La linguistique sociale, a qual permanecerá por muito tempo como o único manual francês de Sociolinguística.

Ora, essa obra estava elaborada conforme um plano um tanto atípico dentre os manuais de Sociolinguística. Além do mérito de ser o primeiro manual francês, ela não é - como muitos daqueles que surgirão mais ou menos na mesma época em outros países, mas também mais tarde na França - constituída somente pela enumeração de capítulos que apresentam teorias (Labov e a variação, Bernstein e os códigos sociolinguísticos, as teorias da variação, a etnografia da comunicação, etc.).

Ela introduz também temas de reflexão de (socio)linguística geral, em torno da problemática "língua e sociedade", ou "relações entre fatos linguísticos e fatos sociais". Assim, nela figura uma parte com cerca de cinquenta páginas, intitulada Position historique du problème: La langue est-elle une superstructure et une phénomène de classe? (pp. 33-87), pretexto para apresentar, entre outras, reflexões de Marr e dos marristas, a partir de um ponto de vista filosófico que considera implicações políticas.

Jean-Baptiste Marcellesi e Bernard Gardin, os autores do manual de 1974, são linguistas marxistas, como era, aliás, uma boa parte dos atores envolvidos no nascimento tanto da Análise do Discurso como da Sociolinguística na França. E se a data de 1977 pode também evocar uma certa tonalidade teórica, a partir de uma conjuntura política (a ruptura da união da esquerda acontece em 1977, pois é em 1981 que Mitterrand será eleito presidente da República), a continuidade dos temas de reflexão relativos à obra de 1974 autoriza outras interpretações, não necessariamente antinômicas aliás.

Nesse período de intensas confrontações de idéias, Marcellesi e Gardin participam ativamente, como muitos linguistas, dos debates do $\mathrm{CERM}^{4}$, que se organizam em torno das interpretações do marxismo (um tema subjacente às discussões assume, por exemplo, a figura de defesa ou de ataque às teses de Althusser). As discussões são ainda mais intensas porque os participantes investem em um ponto de convergência entre o político e o teórico, em uma época em que a problemática política é muito presente entre os intelectuais.

4 Devo a Francine Mazière, que aqui agradeço, a possibilidade de ter consultado arquivos que ela conservou: os dos trabalhos do Centre d'Etudes et de Recherches Marxistes (CERM), que nos anos 1976-1980, compreendia um "Círculo de linguística". A maior parte dos protagonistas cujos nomes aqui se apresentam, que estão entre os atores do nascimento da Sociolinguística e da Análise do Discurso na França, aproximaram-se e, muitas vezes, confrontaram-se, nesses anos, tanto no CERM quanto na universidade, em debates cujos temas foram exatamente tramados pelo número de Langages. O longo artigo de Denise Maldidier (1990) expõe bem a atmosfera de agitação teórica e política que caracterizou esse período. 
Em 1977, o campo da Linguística na França (que será rebatizado de Ciências da linguagem apenas em 1983) encontra-se profundamente dominado por correntes do tipo formalista (estruturalismo e gerativismo), como ainda ocorre hoje. Formulando a situação geral da disciplina nesses termos, eu me coloco, como no artigo que escrevi na revista Langages 46, em uma perspectiva que representa a história da Linguística como uma tensão dinâmica e continuamente reconfigurada entre as duas tendências - o logicismo (ou formalismo) e o sociologismo ${ }^{5}$. A Sociolinguística faz claramente parte da segunda tendência.

\section{Por que um debate?}

Os limites impostos por uma oposição entre tendências permitem considerar que Marcellesi, através de uma reflexão em torno do marrismo, tem como objetivo tornar perene a Sociolinguística. Essa disciplina já existe na época, mas apenas em alguns raros programas universitários franceses, como em Nanterre, onde Dubois leciona e de onde Marcellesi teria saído há pouco para fundar o departamento de Rouen, que se imporá logo como um polo importante da Sociolinguística e da Análise do Discurso.

Esse tipo de operação de fundação ou de (re)habilitação pode se dar de forma negativa, a partir daquilo a que a nova subdisciplina se oporá: um bom exemplo para a Sociolinguística nascente é a exploração excessiva do tema da crítica aos conceitos saussurianos 6 . Mesmo que Marcellesi tenha produzido apenas moderadamente nesse gênero, do qual se serve somente para delimitar os fundamentos, esse é um indício de trabalho de base. De qualquer maneira, serve-se disso bem menos do que outros au-

5 Essa oposição foi apresentada no livro que escrevi com Michel Pêcheux, em 1981. Estamos muito longe de sermos os únicos que expressaram uma abordagem global da história da disciplina sob a forma de uma dicotomia de tendências, como mostram, pelo menos, dois outros exemplos. Rastier (2001), entre outros, opõe o "paradigma lógico-gramatical" ao "paradigma retórico-hermenêutico" (ou interpretativo); e Simone (1990) opõe o "paradigma do arbitrário" ao "paradigma da substância". Nos pontos de intersecção entre as representações de uma dicotomia irredutível e que, ao mesmo tempo, constitui o motor da história da disciplina, há a constância de hegemonia histórica do primeiro paradigma sobre o segundo, de todo modo, ao longo do século XIX.

6 A maneira como perdura tal perspectiva anti-saussuriana, mesmo nos trabalhos de jovens linguistas que não foram particularmente formados na escola suassuriana, constitui um aspecto intrigante da história da Sociolinguística francesa. Contudo, é ilusório situar o surgimento da Sociolinguística, na França como em outros lugares, sob uma crítica racional de Saussure e do estruturalismo: a comparação depende de um fundamento post hoc. A oposição aos conceitos chomskyanos, tomada de Labov no contexto americano, depende do mesmo a posteriori, inscrito na conjuntura dos anos 1970-1980.

Organon, Porto Alegre, v. 30, n. 59, p. 41-53, jul/dez. 2015. 
tores ocupados em fundar a disciplina, que chegaram até a fantasiar uma outra história (por exemplo, com a noção epistemologicamente estranha de "encontro mal-sucedido", se ao menos a corrente sociológica não se encontrasse tão dominada...). Mas uma fundação pode também se dar de maneira positiva, através da busca de antecedentes e/ou de antepassados influentes. É mais nesse segundo comportamento que Marcellesi se inscreve, mas ele não se contentará, para fazê-lo, em valorizar os elementos sociológicos presentes nos trabalhos das épocas anteriores (em paralelo à dominação do estruturalismo), os de Antoine Meillet, de Joseph Vendryès, ou de Marcel Cohen, em particular.

Nesse contexto, o marxismo mostra-se como um candidato possível ao estatuto de antecessor de uma problemática das relações entre língua e sociedade, com uma já longa tradição de levantar problemas, no que tange à relação entre a linguagem, de um lado, e a história, a política (ou o político) ou o social de outro. Aliás, três outras obras que tratam da relação entre marxismo e linguagem são publicadas em francês, também em 1977. Uma delas, intitulada Marxismo e lingüística, retoma textos conhecidos, mas dispersos em diferentes publicações de Marx, Engels, Lafargue e a célebre intervenção de Stalin em torno da questão da língua, e é apresentada por uma longa introdução de Louis-Jean Calvet.

A segunda é o texto de Bakhtin-Volochinov, Marxismo e Filosofia da Linguagem, que data de 1929, e é apresentado pela primeira vez em tradução francesa; aliás, a referência a esse autor, apresentado na obra de Marcellesi-Gardin em 1974, também ocorre nos debates do CERM. A terceira é um livro do filósofo Jean-Louis Houdebine, Langage et marxisme, síntese do pensamento marxista sobre a linguagem.

Houdebine detém-se largamente na controvérsia Marr-Stalin e termina seu percurso em Volochinov, apresentado como "um sopro de pensamento vivo". Esses temas de debate são reproduzidos também, na mesma época, em revistas não estritamente universitárias (de qualquer modo, não com base disciplinar), mas mais filosóficas e políticas (próximas do marxismo), como La Pensée ou Dialectiques.

Podiam as teorias de Marr proporcionar os termos de um debate sobre a linguagem e o social? Sem se deter em aspectos que não podiam resistir ao tempo (como os quatro elementos) e, para além de uma episteme muito acentuada pelo século XIX (como mostra a insistência sobre a origem da linguagem), questões sempre atuais são formuladas em torno da maneira de situar a língua em relação ao funcionamento de uma sociedade e, por consequência, de sua sensibilidade ao social. Mas essas verdadeiras questões 
não foram efetivamente consideradas e se encontraram descartadas após "a intervenção de Stalin", em geral saudada como um "retorno ao bom senso" (ver o conjunto das reações em Baggioni, 1977). A posição adotada por Stalin, de fato, pudera parecer mais tranquilizadora porque seguia as teorias linguísticas dominantes. Do marxismo não vinham mais, assim, interrogações políticas e sociais, mas o que pudesse confirmar a linguística dominante.

Calvet $^{7}$ fala do "alívio" dos linguistas franceses, a quem Stalin vem oferecer uma "garantia de esquerda" para marginalizar as questões políticas, estabelecendo uma certa visão da linguística como ciência ${ }^{8}$. Calvet confirma assim a nota de Girard em Langages 46, para a qual um dos efeitos do texto de Stalin foi liberar os linguistas soviéticos (e os linguistas marxistas ocidentais) de preocupações políticas, permitindo-lhes, por conseguinte, seguir a linguística formalista e seus objetivos de engenharia das línguas, que se tornarão cada vez mais hegemônicos na disciplina.

Vinte e cinco anos após "a intervenção" de Stalin, a situação é mais ou menos igual. Uma grande parte dos linguistas dos anos 1970 encontra-se, de fato, no dilema de conciliar a herança saussuriana de uma autonomia da língua (geralmente expressa, aliás, sob uma forma radical que chamarei, de preferência, de "neo-saussuriana") com seu engajamento político ou cívico e seu interesse pelo marxismo. É então contra o consenso formalista que Marcellesi vem se inscrever, cujo esforço instituidor prosseguirá no ano seguinte (1978) com a organização em Rouen do primeiro grande colóquio de Sociolinguística da França ${ }^{9}$, onde se estabelece, para a disciplina nascente, o princípio da dupla perspectiva: ancoragem teórica e reivindicação de utilidade social (1977).

O conjunto do debate desses anos 1970 em torno do marrismo pode assim ser visto como uma oportunidade de insistir sobre as questões políticas e sociais, estando em jogo o objeto da linguística e a construção de um lugar para uma corrente sociologista.

7 Calvet, 1977, p. 36.

8 Nesse pormenor, as reações dos linguistas marxistas sobre a questão Marr-Stalin devem ser postas em contraste. Em consequência, Marcel Cohen falara, em 1950, de Stalin, que dava uma "lição de marxismo" (Houdebine, 1977), mas sua obra de 1956 é de um tom muito moderado, tanto sobre Marr (lembrado através de sua "teoria ultrapassada", mas não ridicularizada) quanto sobre Stalin (citado como epígrafe, ao lado de Lucrécio e de Meillet, mas cujas teses são a oportunidade de levantar questões teóricas prudentemente formuladas, sem desferir respostas - por exemplo, p. 64 ou p. 111).

9 Marcellesi 1997, p. 182. 


\section{Os linguistas e os grandes debates}

Se o número de Langages sobre o marrismo foi ocasionado por temas para um debate sobre a língua, esse é um acontecimento que se tornou pouco frequente nos dias atuais, especialmente pela rarefação dos lugares de confrontação fora da universidade para conduzi-los.

De fato, os grandes debates ocupam, em suma, um lugar secundário entre os linguistas, mesmo em épocas em que uma fragmentação da disciplina não está excluída. Embora os linguistas apreciem confrontar teorias, eles não buscam os grandes debates, nos quais problemáticas e opções fundamentais se confrontam. Contentam-se com a evidência da existência de uma disciplina Ciências da Linguagem, pressupondo que não há motivo para que ela não perdure, sem que haja questionamentos fundamentais sobre a distribuição dos conhecimentos nas Ciências Humanas, ou sobre a maneira como as Ciências da Linguagem podem ser afetadas em sua própria base por reflexões políticas e filosóficas em torno da língua ${ }^{10}$.

Ora, entre as temáticas relacionadas à linguagem e à (ou às) língua(s) levantadas, nos anos 1920 e 1930, tanto na URSS como fora dela, muitas levantam questões que têm incidências sobre a Linguística geral, que correm pouco risco de desaparecer quando novas questões sociais e políticas relativas à linguagem surgem com a globalização. Porém, o quadro onde tais questões de língua(s) são levantadas quase não é o da Linguística atual na França. Talvez não se possa dizer o mesmo de todos os lugares, a julgar pela existência de trabalhos teóricos como os de Blommaert (1999) ou da linguistic anthropology americana, que retomam textos e temas fundamentais; ou pela formulação de debates práticos e públicos como os apresentados em Heller (1999).

Marcellesi contribui então para o ressurgimento de um debate sobre as relações entre a língua e o social. No entanto, interpelado por correio eletrônico, ele relembra esse período usando justificativas, em suma, anedóticas: sua doutoranda Claudine Lelièvre encontrara na Biblioteca Nacional francesa um dossiê com todos os artigos publicados na época, na URSS (em inglês), e ele tinha por vizinho Jean-Claude Dupas, professor de inglês disponível para fazer traduções ${ }^{11}$. O impacto desses acasos é incontestável. Contudo, o fato de ter convidado em primeiro lugar Jean-Pierre Faye e Alexandre Adler,

10 Gadet, 2004.

11 Aliás, há um ponto que merece ser assinalado acerca desse número de Langages: nenhum dos autores, que nele figuram lê russo. Também essa observação sustenta uma hipótese de apostas epistemológicas francesas, que se mostram superiores a um objetivo descritivo e/ou avaliativo. 
que se retiraram após ter concordado a priori, dá peso à hipótese de um propósito teórico-político, particularmente em relação ao segundo, jornalista e historiador da URSS, mas não especialista em linguagem, ao contrário do primeiro, conhecido por seu interesse pela relação entre a língua e o político. E quando Marcellesi redige, cerca de vinte anos mais tarde, um balanço de sua obra (do mesmo modo que a do coletivo chamado "Ecole de Rouen"), a reflexão sobre o marrismo ocupa nele um lugar significativo ${ }^{12}$.

As questões que levantamos aqui aplicam-se ao modo como o marxismo e o marrismo influenciaram o campo da Sociolinguística nascente, e como essa referência interveio no surgimento da Sociolinguística francesa, em um período dos anos 1970 marcado por esperanças políticas e teóricas que se transformam rapidamente (o que Maldidier (1990) denomina "reviravolta da conjuntura teórica que começa a partir de 1975”).

Essa interseção entre a história e a epistemologia está destinada a se inserir em uma reflexão global sobre a história da Sociolinguística na França, que busca, em particular, compreender por que esta pode revelar-se relativamente singular em comparação, contudo, com a maneira como essa disciplina se manifestou em outros países europeus, como a Itália, a Alemanha ou a Inglaterra. A reflexão marxista não é, evidentemente, a única origem da Sociolinguística francesa, nem mesmo certamente sua origem essencial; ela deve ser situada, antes, nas reconfigurações da dialetologia ou da lexicologia, na descoberta da "dialetologia social" ou da linguística antropológica americanas, ou no estudo do contato entre línguas (em particular, pelos africanistas). Porém, as discussões em torno do marxismo e da política devem certamente ser consideradas para compreender certas especificidades da Sociolinguística francesa, já que, finalmente, debates similares aconteceram apenas em pouquíssimos países europeus e de nenhum modo nos Estados Unidos. Pode-se ler, a esse respeito, o depoimento de Jean Le Dû (2003), que retoma essa origem interpelando de forma espirituosa a jovem geração de sociolinguistas franceses: "E a luta de classes, camaradas?".

\section{Um debate crucial a partir do marrismo}

Os debates soviéticos podem ser vistos como um acontecimento conceitual único ${ }^{13}$, um representando a imagem invertida do outro. Se deci-

12 Marcellesi, 1997 e 2003.

13 Houdebine, 1977, p. 156.

Organon, Porto Alegre, v. 30, n. 59, p. 41-53, jul/dez. 2015. 
dirmos abstraí-los um pouco arbitrariamente de seu contexto histórico, podemos dizer que Marcellesi apropriou-se deles para levantar problemas inerentes ao modo como a linguística delimitou suas fronteiras com as disciplinas afins, o que aconteceu na França de modo singular. Dentre esses problemas, o debate central aplica-se ao modo como o social é correlacionado ao sistema lingüístico. As questões desse debate foram bem (re) formuladas por Sériot (1989), a respeito da relação entre a linguagem estereotipada dos políticos e a verdade: ele acentua o fato de que o reconhecimento de uma ordem própria da língua não deveria levar a concebê-la como autônoma e ainda menos como autárquica. Poderíamos acrescentar que o termo língua, tal como foi formulado no debate tanto nos anos 1950 quanto no nascimento da Sociolinguística francesa, quase não foi objeto de reflexões aprofundadas ${ }^{14}$ (ver Gadet, no prelo).

O lugar central que essa questão ocupa é exemplificado por uma observação formulada por Calvet, em sua introdução de 1977 e, ao mesmo tempo, por Baggioni, no número de Langages. Ambos evocam Mounin que, em sua história da linguística, lamentava a ausência do tema do marxismo na reflexão dos linguistas franceses ${ }^{15}$. Ora, Mounin considera que há uma linguística que repousa sobre bases científicas, neutras: é o estruturalismo (e, no que lhe diz respeito, a versão funcionalista do estruturalismo proposta por Martinet), que pode, como tal, ser posta a serviço de todo tipo de elaboração teórica, como, por exemplo, uma reflexão marxista.

Nessa perspectiva, não restaria mais nada a uma linguística ansiosa por contextualização social do que o expediente de intervir em uma segunda etapa, que será então, necessariamente, a correlação de duas dimensões autônomas. De um lado, uma ordem do linguístico, construído e analisado sem referência ao social (fala-se então de linguística “interna”, segundo a expressão de Saussure) e, de outro, uma ordem do social/histórico(que produzirá o quadro de "fatores externos"), também concebida antes e independentemente de toda expressão linguística. Foi exatamente esse ponto de vista que orientou as primeiras teorizações da Sociolinguística, seja sob uma forma endógena que não leva ainda esse nome, oriunda dos trabalhos de Meillet ou de Cohen, seja sob a forma da "co-variação", recentemente importada dos Estados Unidos (mas à qual, aliás, as duas modalidades retornam).

$14 \mathrm{O}$ texto atribuído a Stalin apresenta mesmo uma definição de língua, mas ela é mínima e constitui a tal ponto um plano banalizado de estruturalismo que é pouco conveniente que seja considerada.

15 Mounin, 1972, p. 230.

Organon, Porto Alegre, v. 30, n. 59, p. 41-53, jul/dez. 2015. 
Ora, em paralelo ao surgimento da Sociolinguística francesa, outra via foi explorada para conceber as relações entre o social e o linguístico. Trata-se de uma via estreita, e a dificuldade para concebê-la se mostra como um dos temas legíveis no número de Langages, mesmo que muitas vezes indiretamente. Trata-se de conceber um nível intermediário entre o social e um sistema de língua autônomo e não dependente do social, tal como herdado da linguística neo-saussuriana: esse será o discurso. Tarefa extremamente difícil, a partir do momento em que, como no estruturalismo, a língua como sistema resta também levemente alterada pelo social. $\mathrm{Na}$ França, será a Análise do Discurso, mais do que a Sociolinguística, a responsável pelas tentativas de explorar essa idéia. Ao se constituir, a Sociolinguística francesa, de fato, conceberá maciçamente a língua como um "reflexo" do social, o que lhe vale as críticas da Análise do Discurso, pelo menos aquela proveniente dos trabalhos de Pêcheux ${ }^{16}$. Esse debate ultrapassa, assim, tanto a Sociolinguística quanto a Análise do Discurso e diz respeito à Linguística Geral no que concerne à relação da língua com seu exterior. Diante do impasse constituído por uma concepção muito formalista do discurso, nessa conjuntura dos anos 1970 formulada sem considerar o usual e o oral, bem como todos os aspectos de manifestação do social que os acompanham, a Análise do Discurso, voltada para o arquivo e apoiada na história, conseguiu mostrar-se mais segura conceitualmente, pois oferecia uma ancoragem contextual e ecológica que a Sociolinguística situava apenas nos "fatores externos", teorizados somente através de uma sociologia espontânea rudimentar.

Um questionamento da comunicação enquanto codificação/decodificação bem-sucedida (com o risco de tornar o locutor deliberadamente senhor de suas produções na enunciação e admitindo o significado tal como foi desejado pelo outro), que dá acesso ao discurso como lugar de uma subjetividade estruturada e de organização de mal-entendidos, de tensões e de conflitos, conduz a examinar aquilo que os locutores de diferentes grupos sociais fazem ao enunciar. Eles dizem o mesmo, dizendo de maneira diferente? Ou a diferença das formulações, determinada por diferenças de posições enunciativas, leva a produzir sentido diferente? ${ }^{17}$ Essa dicotomia atravessa todas as disciplinas linguísticas ligadas à interpretação e perdura na Análise do Discurso de tendência lexicológica com as questões de investimentos de palavras (por exemplo, a "neutralidade ideológica" da palavra em Volochinov)

16 Pêcheux, 1975, Gadet \& Pêcheux, 1981, Maldidier, 1990, Mazière, 2005.

17 Pêcheux, 1975, ao menos para a produção da questão. 


\section{Conclusão}

Marcellesi \& Gardin, em sua obra de 1974 (p. 248), encerraram o debate em torno do marrismo com uma prudência evidente, particularmente pelo uso reiterado de negações, que assinalam como o problema perdura sem solução:

"Não é verdade que a língua não é determinada parcialmente pela superestrutura; mas tampouco é verdade que a língua é apenas uma superestrutura; "Não é verdade que a língua é apenas um fenômeno de classe; não é verdade, no sentido inverso, que a língua nunca serve aos interesses de classe".

Apesar da crítica de Baggioni (1977), que censura essa prudência que ele considera excessiva, podia ser de outro modo? Com esse nem...nem, não é exatamente um espaço duplamente negativo da via estreita do sociolinguístico que eles traçam (considerando a língua, mas sem ser a Linguística; considerando o social, mas sem ser as ciências sociais?) Efetivamente, em sua forma pura, nenhuma das duas posições pode ser produtiva, e compreende-se que esses autores (mais Gardin do que Marcellesi) tenham buscado uma via em Volochinov e fazer dele um precursor da Sociolinguística.

Um problema discutido em outro contexto histórico e epistemológico foi capaz assim de tornar-se o suporte de expressão de duas dificuldades distintas, na França:

- a dificuldade, para linguistas profundamente marcados por uma epistemologia estruturalista e neo-saussuriana, de conceber a ligação entre duas ordens colocadas, de imediato, como exteriores uma à outra, e de correlacioná-las: o sistema linguístico e os "fatos sociais";

- a dificuldade, para uma Sociolinguística que permaneceu, efetivamente, sob a influência do estruturalismo neo-saussuriano, de oferecer um estatuto aos problemas de constituição dos dados (sua natureza e sua materialidade) e de integrar os mecanismos sociais no linguístico, começando assim uma ordem do sociolinguístico.

Se hoje parece mais fácil do que em 1977 ter consciência dessas dificuldades e ver que o debate em torno do marrismo levava a tantos impasses que quase só vale pela oportunidade que pode apresentar, é porque agora aceita-se mais que o encontro do linguístico e do social (o sociolinguístico) possa ser apreendido a partir do oral, da conversação e do usual, já que o social se manifesta assim, primeiramente, de modo relacional e dinâmico. 


\section{BIBLIOGRAFIA}

BAGGIONI, Daniel. Contribution à l'histoire de l'influence de la Nouvelle Théorie du Langage en France. Langages, 1977, nº 46, p. 90-117. BAKHTINE, Mikhail (VOLOCHINOV Valentin). Le marxisme et la philosophie du langage, Essai d’application de la méthode sociologique en linguistique, Paris: Editions de Minuit, 1977 (Original: 1929).

BLOMMAERT, Jan (Ed.). Langage Ideological Debates, Berlin/New York: Mouton de Gruyter, 1999.

CALVET, Louis-Jean. Sous les pavés de Staline, la plage de Freud? Présentation à: Marxisme et linguistique, Paris: Payot, , 1977:, p. 7-40. COHEN, Marcel. Matériaux pour une sociologie du langage. Paris: Maspéro, 1956: tome 1.

GADET, Françoise. Théorie linguistique ou réalité langagière. Langages, 1977, no 4, p. 59-89.

Mais que font les sociolinguistes. Langage et société, nº 107, 2004, p. 85-94.

. à paraître: Les changements en français actuel: points de vue d'analyse de discours et de sociolinguistique. Actes du $1^{\circ}$ Seminario de Estudos em Analise de discurso, Porto Alegre (10-13 novembre 2003). GADET, Françoise; PÊCHEUX, Michel. La langue introuvable, Paris: Maspéro, 1981.

GIRARD, Nicole. Annexe sur une explication à l'intervention de J. Staline, ou la raison technologique. Langages, 1977, $\mathrm{n}^{\circ} 46$.

HELLER, Monica. Sociolinguistics and public debate. Ebonics, language revival, la qualité de la langue and more: What do we have to say about the language debates of our time. Journal of Sociolinguistics 3/2, 1999, p. 260 88.

HOUDEBINE, Jean-Louis. Langage et marxisme. Paris: Klincksieck, 1977. LAFARGUE, Paul. 1894: La langue française avant et après la Révolution, Ere nouvelle. Republié dans Calvet, 1977, p. 77-144.

LE DU, Jean. Témoignage. in P. Blanchet et D. de Robillard (dirs.), Langues, contacts, complexité. Perspectives théoriques en sociolinguistique, Cahiers de sociolinguistique $\mathrm{n}^{\circ}$ 8, Presses de l'Université de Rennes, 2003, p. 267-72.

MALDIDIER, Denise. (Re)lire Michel Pêcheux aujourd'hui, in L'inquiétude du discours, Textes de Michel Pêcheux. Paris: Editions des cendres, 1990: p. 7-91. MARCELLESI, Jean-Baptiste (dir). Langage et classes sociales: le marrisme, Langages, 1977, nº 46. 
. A propos du marrisme. Langages, $\mathrm{n}^{\circ} 46,1977$, p. 3-22. Contribution to the History of Sociolinguistics: Origins and Development of the Rouen School, in C. Paulston \& R. Tucker (Eds.), The Early Days of Sociolinguistics, Summer Institute of Linguistics Publications in Sociolinguistics, 1977, p. 177-88. . Sociolinguistique française, combien d'années in P. Blanchet et D. de Robillard (dirs), Langues, contacts, complexité. Perspectives théoriques en sociolinguistique $\mathrm{n}^{\circ} 8$, Presses de l'Université de Rennes, 2003, p. 272-8. MARCELLESI, Jean-Baptiste; GARDIN, Bernarde. Introduction à la sociolinguistique. La linguistique sociale, Paris: Larousse, 1974. MAZIERE, Francine. Lanalyse du discours. Histoire et pratique, Paris, PUF,Que sais-je, 2005.

MUNIN, Georges. La linguistique au XX $X^{e}$ siècle. Paris: PUF, 1972. PECHEUX, Michel. Les vérités de la Palice, Paris: Maspéro, 1975. RASTIER, François. Arts et sciences du texte, Paris: PUF, 2001. SERIOT, Patrick. La langue est-elle fasciste? in G. Drigeard, P. Fiala \& M. Tournier, Courants sociolinguistiques, Paris: Klincksieck, 1989, p. 157-67. SIMONE, Raffaele. The body of language. The paradigm of substance and the paradigm of arbitrariness, in R. Amacker \& R. Engler (dir.): Présence de Saussure, Genève: Droz, 1990, p. 121-41.

Recebido em: 26/06/2015. Aceito em: 21/07/2015. 